Rev. Saúde pübl., S. Paulo

8: $87-92,1974$.

\title{
O CONSUMO DE VITAMINA A EM RIBEIRA, SÃO PAULO (BRASIL)
}

Avany Maria Xavier BON ** Maryland MIGUEL **

Bon, A. M. X. \& Miguel, M. - O consumo de vitamina A em Ribeira, São Panlo (Brasil). Rev. Saúde públ., S. Paulo, 8: 87-92, 1974.

Resumo: Foi evidenciado o problema da baixa adequação de vitamina $A$, em localidade considerada grande produtora de alimento rico nesse nutriente, a cidade de Ribeira (S. Paulo, Brasil), produtora de mamão (Carica Papaya L.). A análise dos dados evidencia que esse alimento, que poderia contribuir para cobrir as necessidades recomendadas de vitamina $A$, foi consumido em quantidades infimas. Atribuiu-se esse fato, à falta de conhecimento por parte da população local, do valor nutritivo dos alimentos ricos em vitamina $A$. Recomenda-se o desenvolvimento de campanhas de educação alimentar.

Unitermos: Vitamina $A *$; São Paulo, Brasil *; Nutrição*.

I N T RODUCA O

A vitamina A, como vitamina previamente formada ou como caroteno, participa de forma importante no mecanismo da visão, na integridade dos tecidos epiteliais e no crescimento normal das células epiteliais. Tem efeito. também, sobre o (rescimento normal das estruturas ósseas e dos dentes durante o desenvolvimento ${ }^{1}$.

Em muitas regiōes, onde o nível de vida da maioria da população é baixo, o consumo de vitamina $A$ é inferior ao recomendado. É o que se observa nas zonas do Caribe, América Central e América do Sul, onde o indice de xeroftalmia é elevado. A fai- xa etária mais atingida por essa deficiência, é aquela situada entre 6 meses e 4 anos de idade ${ }^{2}$.

Apesar de sabermos que a carência de vitamina $A$ é mais comum entre os grupos da população que pertencem a baixo nível sócio econômico e que, consequentemente, se alimentam mal e vivem em más condições sanitárias ${ }^{\ddagger}$, deremos lembrar que existem localidades onde há abundância de alimentos ricos nesse nutriente e no entanto a população apresenta grandes deficits no consumo.

* Trabalho apresentado no 6.0 Congresso Brasileiro de Nutricionistas, 3.0 Congresso Brasileiro de Nutrição e 1.a Reuniāo Brasileira sobre a Formação de Nutricionistas, São Paulo, 1972

* Do Departamento de Nutrição da Faculdade de Saúde Pública da Universidade de São Paulo - Av. Dr. Arnaldo, 715 - São Paulo, SP — Brasil. 
BON, A. M. X. \& MIGUEL, M. - O consumo de vitamina A em Ribeira, såo Paulo (Brasil). Rev. Saúde públ., S. Paulo, 8: 87-92, 1974.

Já em 1963, GandRA *, realizou inquérito clínico na região Amazônica do Peru e constatou casos de xerose, de manchas de Bitot, de hiperqueratose folicular, em indivíduos que residiam em casas, cuja planta de ornamentação era o buriti (mauritia flexuosa), fonte de vitamina $A$.

Baseado nesse fato, surgiu então a curiosidade de saber se é a falta de fontes naturais locais que contribui para o consumo insuficiente de vitamina $A$, ou se o problema está mais ligado à educação alimentar, no caso de populações que embora vivendo em áreas com alimentos ricos nesse nutriente, apresentam um consumo deficiente.

\section{O B J E T I V O}

Verificar, em uma área produtora de alimentos ricos em vitamina $A$, se a dieta da comunidade apresenta uma adequação média desse nutriente que atinja os $100 \%$ recomendados pela FAO.

\section{A T E R I A L}

Para realização deste trabalho, nos baseamos nos levantamentos efetuados pelo Departamento de Nutrição da Faculdade de Saúde Pública da Universidade de São Paulo, no ano de 1970, no município de Ribeira que, segundo a Secretaria da Agricultura do Estado de São Paulo, teve nesse ano uma produção de mamão de $2.015 .000 \mathrm{~kg}$, alimento rico em vitamina A (caroteno).

0 território municipal pertence à região do Vale do Ribeira e está localizado bem ao sul do Estado de São Paulo, na divisa com o Estado do Paraná, totalmente dentro da Bacia do rio Ribeira, com uma área de $818 \mathrm{~km}^{2}{ }^{5}$

0 município de Ribeira é formado pelos distritos de Ribeira e de Itapirapuã.
Este trabalho refere-se apenas aos distrito de Ribeira que, conta segundo o censo de 1970 , com uma população de 4.521 habitantes, dos quais 432 se encontram na zona urbana. ${ }^{5}$

$\mathrm{Na}$ região sudoeste, são encontrados extensos maciços florestais, onde existem companhias madeireiras atuando intensamente. É um município tipicamente madeireiro. ${ }^{5}$

A exploração pecuária praticamente não existe. ${ }^{5}$

0 município ressente-se da falta de estradas e as poucas existentes estão mal localizadas em relação à sede. A única estrada de primeira categoria, asfaltada, é a que liga Ribeira a Apiaí. ${ }^{5}$

A exploração agrícola é restrita, sendo constituída por pequenas glebas disseminadas pelo município. Não existe o emprego de variedades selecionadas, adubos ou preparo de terra. As plantações mais comuns são as de milho, feijão e mandioca. ${ }^{5}$

Com referência às culturas permanentes, as maiores exploraçōes são as do mamoeiro (Carica Papaya L.). A cultura se localiza próxima da cidade de $\mathrm{Ri}$ beira, junto à confluência do ribeirão $\mathrm{Ti}$ juca com o Ribeira, subindo até alguns quilômetros acima deste local. ${ }^{5}$

A exploração do mamoeiro está condicionada pelo mercado consumidor de Curitiba onde, devido ao clima, essa cultura não se desenvolve. 0 transporte é feito por caminhão, porém o acondicionamento não é adequado. 0 fornecimento da fruta para São Paulo não é econômico ( 350 $\mathrm{km})$, pois sofre concorrência de outras áreas produtivas. ${ }^{5}$

Essa cultura é propiciada pelo clima da região, que é quente e não sofre ação de geadas. ${ }^{5} \mathrm{O}$ mamoeiro como planta tropical, tem encontrado condiçôes favoráveis em grande parte do Estado, como

- Informação pessoal do Dr. Yaro Ribeiro Gandra da Faculdade de Saúde Pública da Un1versidade de Såo Paulo. 
BON, A. M. X. \& MIGUEL, M. - O consumo de vitamina A em Ribeira, São Paulo (Brasil). Rev. Saúde públ., S. Paulo, 8: 87-92, 1974.

vem acontecendo nos municípios de Ribeira e de Monte Alto. ${ }^{5}$

Atualmente é cultura economicamente recomendável, não só pelo fato de possuir ciclo vegetativo curto e durante $o$ ano todo, como também pela boa aceitação no mercado consumidor e ainda pelas possibilidades industriais que apresenta. ${ }^{5}$

\section{$M=T O D O$}

Os dados utilizados neste trabalho foram levantados através de inquérito alimentar.

$O$ inquérito foi realizado na zona urbana da cidade de Ribeira, retirando-se da população de famílias ou domicílios uma amostra casual simples, que correspondeu a 28 famílias $(18 \%)$.

Para a obtenção dos dados, utilizou-se o método das pesadas "um dia sete dias". ${ }^{3}$
RESULT A D S

Composição populacional (Tabela 1): das 28 famílias que compuseram a amostra, com um total de 197 pessoas, 51\% pertenciam ao sexo masculino e $49 \%$ pertenciam ao sexo feminino. Em média, encontramos 7 pessoas por família.

Os resultados do inquérito alimentar, quanto aos alimentos consumidos em média, por dia, per capita, e a quantidade média diária per capita, em microgramas de vitamina A ativa, dos alimentos de origem animal e vegetal consumidos em Ribeira, encontram-se na Tabela 2.

$O$ consumo e a necessidade médios diários de nutrientes por indivíduo, achamse na Tabela 3.

\section{COMENTARIOS E CONCLUSOES}

Pelos resultados, pudemos verificar que realmente a regiáo embora sendo produ-

TABELA 1

Composição populacional, Ribeira - 1970

\begin{tabular}{|c|c|c|c|c|c|c|}
\hline \multirow{2}{*}{\multicolumn{2}{|c|}{ Grupo }} & \multirow{2}{*}{ etário } & \multicolumn{2}{|c|}{ Sexo } & \multicolumn{2}{|c|}{ Total } \\
\hline & & & masculino & feminino & n. ${ }^{\circ}$ de ina. & $\%$ \\
\hline 4 & $1-1$ & 9 meses & 1 & 2 & 3 & 1,0 \\
\hline 1 & $1-1$ & 3 anos & 10 & 8 & 16 & 9,0 \\
\hline 4 & $1-1$ & 6 anos & 10 & 3 & 13 & 6,0 \\
\hline 7 & $1-1$ & 9 anos & 11 & 7 & 18 & 9,0 \\
\hline 10 & $1-1$ & 12 anos & 6 & 15 & 21 & 11,0 \\
\hline 13 & $1-1$ & 15 anos & 11 & 11 & 22 & 11,0 \\
\hline 16 & $1-i$ & 19 anos & 11 & 7 & 18 & 9,0 \\
\hline 20 & $1-1$ & 29 anos & 17 & 17 & 34 & 17,0 \\
\hline 30 & $1-1$ & 39 anos & 9 & 10 & 19 & 10,0 \\
\hline 40 & $1-i$ & 49 anos & 7 & 7 & 14 & 7,0 \\
\hline 50 & $1-i$ & 59 anos & 5 & 6 & 11 & 5,0 \\
\hline & $1-1$ & 69 anos & 3 & - & 3 & 1,0 \\
\hline 70 & $1-i$ & 79 anos & 一 & 3 & 3 & 1,0 \\
\hline \multicolumn{3}{|c|}{ Total } & 101 & 96 & 197 & \\
\hline \multicolumn{3}{|c|}{ Porcentagem } & $51 \%$ & $49 \%$ & $100 \%$ & \\
\hline
\end{tabular}


BON, A. M. X. \& MIGUEL, M. - o consumo de vitamina A em Ribeira, São Paulo (Brasil). Rev. Saúde públ., S. Paulo, 8: 87-92, 1974.

TABELA 2

Consumo médio dírio de alimentos e vitamina A por individuo, Ribeira - 1970

\begin{tabular}{l|c|c}
\hline Alimentos & $\begin{array}{c}\text { Consumo médio diário } \\
\text { por individuo } \\
\text { g }\end{array}$ & $\begin{array}{c}\text { Consumo médio diário } \\
\text { por individuo de } \\
\text { vitamina A ativa } \\
\text { meg }\end{array}$ \\
\hline
\end{tabular}

Abobrinha

Acúcar

Alface

Alho

Almelrão-Escarola

Arroz polldo

Bacalhau salgado

Banana

Banha de porco

Batata inglesa sem casca

Bolacha

Café infusāo $1 \%$

Café infusāo $2 \%$

Café infusão $3 \%$

Café infusão $4 \%$

Cafe infusão $5 \%$

Café infusão $6 \%$

Carne de cabrito

Carne de frango

Carne de porco média

Carne de vaca média

Cebola

Cenoura

Chuchu

Couve-flor

Couve-manteiga

Farinha láctea

Farinha de milho amarela

Farinha de trigo

Feljão comum

Fuba

Groselha

Jabuticaba

Laranja tresca

Leite pó integral

Leite vaca tipo 1

Limāo

Linguiça mista

Maçã

Masarrăo

Maizena

Mamăo maduro

Margarina

Massa de Tomate

Melancia

Mortadela

Oleo vegetal

Ovo-galinha-gema

Ovo-galinha-inteiro

\begin{tabular}{|c|c|}
\hline 1,69 & 0,25 \\
\hline 72,24 & - \\
\hline 2,76 & 7,18 \\
\hline 0,88 & 0,04 \\
\hline 2,39 & 18,88 \\
\hline 116,82 & - \\
\hline 0,66 & $\ldots$ \\
\hline 15,73 & 7,86 \\
\hline 22,09 & - \\
\hline 20,12 & - \\
\hline 0,39 & - \\
\hline 126,24 & - \\
\hline 253,86 & - \\
\hline 92,50 & - \\
\hline 36,11 & - \\
\hline 16,54 & - \\
\hline 11,03 & - \\
\hline 1,93 & - \\
\hline 33,18 & - \\
\hline 10,87 & - \\
\hline 13,72 & - \\
\hline 4,92 & 0,25 \\
\hline 0,28 & 9,88 \\
\hline 4,98 & 0,25 \\
\hline 3,86 & 0,39 \\
\hline 5,15 & 103,77 \\
\hline 0,53 & 2,38 \\
\hline 13,99 & 28,26 \\
\hline 18,84 & - \\
\hline 64,00 & 3,20 \\
\hline 1,86 & 0,21 \\
\hline 0,11 & - \\
\hline 5,83 & - \\
\hline 0,39 & 0,17 \\
\hline 2,79 & 7,11 \\
\hline 44,27 & $.13,28$ \\
\hline 0,53 & 0,03 \\
\hline 5,18 & 0,78 \\
\hline 0,72 & 0,07 \\
\hline 15,52 & - \\
\hline 0.11 & - \\
\hline 11,09 & 12,20 \\
\hline 0,80 & 2,88 \\
\hline 5,01 & 10,00 \\
\hline 5,08 & 3,56 \\
\hline 0,28 & 一 \\
\hline 7,12 & - \\
\hline 0,11 & 0,82 \\
\hline 13,81 & $\mathbf{1 7 7 , 2 6}$ \\
\hline
\end{tabular}


BON, A. M. X. \& MIGUEL, M. - O consumo de vitamina A em Ribelra, Såo Paulo (Brasil). Rev. Saude puibl., S. Paulo, 8: 87-92, 1974.

T A B E A 2 (Continuação)

\begin{tabular}{|c|c|c|}
\hline Alimentos & $\begin{array}{c}\text { Consumo médio diário } \\
\text { por individuo } \\
\mathbf{g}\end{array}$ & $\begin{array}{c}\text { Consumo médio diário } \\
\text { por individuo de } \\
\text { vitamina A ativa } \\
\text { meg }\end{array}$ \\
\hline Palmito & 1,98 & - \\
\hline Păo & 53,25 & 2,86 \\
\hline Pimentão & 1,97 & 0,02 \\
\hline Pipoca & 0,44 & - \\
\hline Polvilho & 1,10 & - \\
\hline Rabanete ralz & 0,33 & - \\
\hline Rapadura & 0,11 & 1,24 \\
\hline Repolho & 4,14 & - \\
\hline Sardinha lata azeite & 0,77 & 0,44 \\
\hline Tomate & 15,76 & 28,37 \\
\hline
\end{tabular}

Obs.: Baseado ra Tabela de Composiç̃o de Alimentos, Sāo Paulo, compilada pelo Departamento de Nutrição da Faculdade de Saúde Pública da Universidade de São Paulo.

tora de mamão, alimento considerado fonte de vitamina $A$, apresenta um deficit de consumo acentuado desse nutriente.

De acordo com Tabelas de composição química dos alimentos, temos que $100 \mathrm{~g}$ de mamão maduro fornecem $110 \mathrm{mcg}$ de vitamina A ativa.

Considerando que a necessidade média, diária, per capita da comunidade foi de $1.270 \mathrm{mcg}$ de vitamina $A$, um indivíduo consumindo pelo menos uma fatia de cerca de $300 \mathrm{~g}$ desse alimento, preencheria $1 / 4$ da suas necessidades.

No entanto, esse alimento que por ser abundante na região, poderia cobrir grande parte das necessidades diárias de vitamina $A$, talvez devido ao desconhecimento de seu valor nutritivo, por parte da comunidade, contribuiu apenas com $0,96 \%$ das necessidades recomendadas.

Concluimos, portanto, que nessa região, um programa de educação alimentar seria altamente recomendável para a melhoria da adequação de vitamina A na dieta.
Geralmente a seleção de alimentos é feita de acordo com as preferências e hábitos alimentares da família e padrões culturais regionais. Portanto, somente a disponibilidade de gêneros alimentícios, não leva uma população a um consumo alimentar adequado, pois Ribeira com uma produção anual de mamão igual a 2.015 toneladas em 1970, teve um consumo médio diário por indivíduo de apenas $11,09 \mathrm{~g}$.

Mesmo que a produção de alimentos numa determinada região tenha tendências a aumentar, como é o caso do mamão em Ribeira, que até o mês de setembro de 1972 já havia atingido 4.340 toneladas, sem o desenvolvimento de programas educativos de nutrição que transmitam conhecimentos básicos, que corrijam informaçōes errôneas, e que ensinem aos indivíduos o aproveitamento adequado dos alimentos locais não conseguiremos melhoria do nível de saúde da comunidade. 
BON, A. M. X. \& MIGUEL, M. - o consumo de vitamina A em Ribeira, São Paulo (Brasij). Rev. Saúde públ., S. Paulo, 8: 87-92, 1974.

Bon, A. M. X. \& Miguel, M. - [The consumption of vitamin A in Ribeira, S. Paulo (Brazil).] Rev. Saúde públ., S. Paulo, 8: 87-92, 1974

SUMmARY: It was focused the problem of low adequacy of vitamin $A$, in an area considered as a great producer of foodstuff rich in this nutrient, the city of Ribeira, S. Paulo (Brazil), that is a large scale producer of Papaya (Carica papaya L.). The analysis of the data, pointed out that this foodstuff that would amply cover the recommended necessities of Vitamin $A$, was consumed in insignificant quantities. This fact was attributed to a lack of knowledge of the local population on the nutritive value of foodstuff rich in vitamin $A$. Consequently it was recommended, the development of food education programs, in the mentioned town.

UNITERMS: Vitamin $A *$; S. Paulo, Brazil*; Nutrition.

\section{REFERENCIAS BIBLIOGRAFICAS}

1. BURTON, B. - Nutricion humana. 2. ed. Washington, D.C., OPAS, 1968. (Publ. Cient. 146).

2. MC LAREN, D. S. et al. - Ocular manifestations of vitamin A deficiency in man. Bull. Wld. Hlth. Org., 34: 357-61, 1966.

3. MIGUEL, M. \& BON, A. M. X. - Resultados do inquerito alimentar nas cidades de Apiat, Ribeira e Barra do Chapéu. São Paulo, Dept.o de Nutrição da Faculdade de Saúde Pública da USP, 1972.

4. RONCADA, M. J. - Contribuicão para o estudo da hipovitaminose A-Niveis séricos de vitamina $A$ e caroteno em três populações litorâneas do Estado de São Paulo: Iguape, Icapara $e$ Pontal do Ribeira. São Paulo, 1971. [Monografía de mestrado - Faculdade de Saúde Pública da USP].

5. SAO PAUlo (Estado) - Departamento de Aguas e Energia Elétrica. Serviço do Vale do Ribeira. Plano de desenvolvimento do Vale do Ribeira e Litoral Sul. São Paulo, Brasconsult, 1966. v. 3 e 4

Recebido para publicacão em 17-12-1973.

Aprovado para publicacão em 27-1-1974. 